\title{
Citocinas en la salud del adulto mayor
}

\author{
Cytokines in the health of the elderly
}

Jasmina M. Correa Alfaro' ; Tatiana M. Echavarría Hernández

Tutor: Jairo L. Cardona Jiménez²

\section{Resumen}

El envejecimiento está asociado con un incremento en los niveles de citocinas catabólicas y con la declinación de la inmunidad humoral. Estas citocinas desempeñan un papel importante en el estado de salud de los adultos mayores, regulando la respuesta inmunológica ante estímulos estresantes tanto físicos como psicológicos. Se revisaron 56 artículos académicos en inglés y en español, publicados entre los años 1998 y 2015. Se utilizaron bases de datos de la Ebsco, Access Medicine, PubMed, MedlinePlus, Elsevier, Llilacs, Cochrane, Scielo y Bireme. Con esta revisión se logró una perspectiva general sobre las citocinas y su funcionamiento en el adulto mayor.

Como resultado relevante se destaca que el sistema inmunológico presenta un deterioro y una disminución de la inmunidad, tanto innata como adquirida en la respuesta inflamatoria, aumentando la incidencia de infecciones $y$, a su vez, incrementando los factores de riesgo que fomentan la fragilidad, las hospitalizaciones, las enfermedades crónicas y las degenerativas. Por otra parte, el ejercicio y la administración de una dieta adecuada afectan positivamente la producción de citocinas, mejorando el rendimiento físico y fortaleciendo el sistema inmune. Precisar la capacidad de las citocinas para influir en el estado de salud y los posibles mecanismos implicados en patologías médicas, abre una amplia gama de posibles objetivos farmacológicos y conductuales que pueden ser blancos para el desarrollo de nuevos tratamientos y estrategias de prevención que permitan incrementar la calidad de vida de los ancianos. 
Palabras clave: adulto mayor, anciano frágil, citocinas, estado de salud, sistema inmunológico.

\section{Abstract}

Aging is associated with increased catabolic cytokine levels and a decline in humoral immunity. These cytokines play an important role in the health of the elderly, regulating the immune response to stressful stimuli both physical and psychological. A total of 56 papers, published between 1998 and 2015, written either in English or Spanish, were examined. The papers were searched for in EBSCO, Access Medicine, PubMed, MedlinePlus, Elsevier, Llilacs, Cochrane, Scielo and Bireme databases. This review provided an overview of cytokines and their functioning in the elderly. The most noteworthy finding of this review was an impairment of the immune system with decreased immunity, both innate and acquired, in the inflammatory response, thus increasing the incidence of infections and, in turn, increasing the risk factors which promote frailty, hospitalizations and chronic and degenerative diseases. On the other hand, exercising and adopting a proper diet positively affect cytokine production, improving physical performance and strengthening the immune system. Clarifying the ability of cytokines to influence health status as well as the possible mechanisms underlying medical conditions, opens a wide range of potential pharmacological and behavioral objectives that can be aimed for in order to develop new treatments and prevention strategies allowing to enhance life quality of the elderly.

Keywords: elderly, frail elderly, cytokines, health status, immune system.

\section{Introducción}

Desde el descubrimiento del interferón Gamma (IFN y) en 1957 y, posteriormente, el factor in- hibidor de macrófagos como primera linfocina, se ha establecido una importante relación de las citocinas (término formalizado en 1974) con los diferentes procesos del sistema inmune (Filella X, 2002). Sin embargo, en la actualidad se siguen descubriendo diferentes moléculas funcionales o citocinas liberadas de células de tejidos diferentes a los inmunológicos. Un ejemplo de ello son las adipoquinas (liberadas de los adipocitos) y las miocinas (liberadas de los miocitos), las cuales cumplen funciones diversas que facilitan los procesos fisiológicos normales que mantienen un proceso de envejecimiento saludable.

Las citocinas son glocoproteinas sintetizadas y excretadas por las diferentes células del cuerpo humano, caracterizadas por realizar funciones de segundo mensajero que dependen del tipo de célula que las libera y de la región donde se llevará a cabo la acción. Pueden ser clasificadas de acuerdo con el estímulo que genere, bien sea proinflamatorio y antiinflamatorio. De igual forma, las podemos clasificar por su nomenclatura -acordes con el tipo de célula que las libera- como interleucinas (células hematopoyéticas), linfocinas (linfocitos), monocinas (monocitos) o conforme al sitio donde generarán su acción, ya sea autocrina (sobre la propia célula), paracrina (en el tejido circundante), endocrina (en tejidos distantes) (Aguirre de Ávalos M. V, 2002).

Cada citocina conforma una red integrada para inducir su propia síntesis y, a su vez, inducir la síntesis de otras citocinas proinflamatorias, incluyendo el TNF- $a$, IL-1 $\beta$ e IL-6.3, produciendo así efectos agonistas, sinérgicos o antagónicos para alterar funcionalmente a la célula blanco, regular la duración y la amplitud de la respuesta inmune, lograr regeneración tisular y la angiogénesis con la estimulación de inmunoglobulinas (Cardella H. L., 1999; Cotran R. S., 1999). 
Para este artículo se revisan diversas publicaciones científicas referentes al efecto de las citocinas en el adulto mayor, ya que este hace parte de una población vulnerable y susceptible de múltiples patologías en la que se observa la interacción y la función de las citocinas en diferentes órganos o patologías médicas, bien sea por medio de un efecto negativo o positivo que se pueda emplear en futuros tratamientos (Guirao y Alonso, 2006).

\section{Resultados}

La construcción de esta revisión temática se fundamenta en el papel de las citocinas en el adulto mayor. La búsqueda bibliográfica se orientó a una selección de artículos especializados, fiables y con validez científica. Como criterios de inclusión y exclusión se eligieron factores tales como: la edad, el tipo de enfermedad, la presencia de otros trastornos, la fecha de publicación (enmarcada entre los años de 1998 y 2015) y la utilización de términos clave, como: «inflammatory response cytokines in elderly", "citocinas en el adulto mayor», «enfermedad del adulto mayor», "alteración de citocinas en adulto" , "función de las citocinas» $\mathrm{y}$ «efectos de las citocinas en el adulto mayor». Se encontraron 70 artículos de los cuales se eligieron 56 que se incorporaron a la revisión; de ellos, 54 están escritos originalmente en inglés (todos se tradujeron al español) y dos en idioma español. Se extrajo esta información de fuentes documentales que hacen referencia directa a literatura científica, bases de datos y buscadores virtuales médicos tales, como: Ebsco, Access Medicine, PubMed, MedlinePlus, Elsevier, Lilacs, Cochrane, Scielo y Bireme.

En la fase de evaluación y análisis de los resultados se organizó estratégicamente la información para recrear un escrito crítico en tres etapas. Al analizar los artículos, se construyó la tabla «Efectos de las citocinas en el adulto mayor» (Tabla 1), donde se presenta un esquema global que sintetiza la revisión bibliográfica y facilita el conocimiento de los aportes a la ciencia en función de las citocinas y de los efectos de estas en la salud de los adultos mayores. No se clasifican los datos de esta tabla según el tipo de citocinas porque cada uno de ellos contiene citocinas que pertenecen a diferentes grupos y se repetiría el artículo varias veces. En este sentido, el orden en que se citan las referencias de cada investigación es cronológico lineal; se consignan los nombres de los autores y del artículo; el tipo de citocina con un signo «+» (si esta interviene en el proceso inflamatorio como citocina proinflamatoria) o «-» (si su efecto es antiinflamatorio); y por último, las conclusiones de cada estudio.

Tabla 1. Efectos de las citocinas en el adulto mayor.

\begin{tabular}{|c|c|c|c|}
\hline Autores & Nombre del artículo & Citocina & Resultados \\
\hline $\begin{array}{c}\text { (Burón Martínez } \\
\text { E., Blanco Quirós } \\
\text { A., Garrote J. A., } \\
\text { Oyagüez P., y L., } \\
\text { 1998) }\end{array}$ & $\begin{array}{l}\text { Citocinas y displasia } \\
\text { broncopulmonar }\end{array}$ & $\begin{array}{l}\text { PDGF, } \\
\text { bFGF, } \\
\text { IGF-1 }\end{array}$ & $\begin{array}{l}\text { Las citocinas son esenciales en el control, manteni- } \\
\text { miento de la inflamación y en la remodelación de te- } \\
\text { jidos lesionados. Se sugiere que las citocinas PDGF } \\
\text { bFGF, IGF-1 están implicadas en el proceso de repa- } \\
\text { ración tisular en adultos que cursan con fibrosis pul- } \\
\text { monar. }\end{array}$ \\
\hline
\end{tabular}




\begin{tabular}{|c|c|c|c|}
\hline Autores & Nombre del artículo & Citocina & Resultados \\
\hline $\begin{array}{c}\text { (Hasegawa, Sawada, } \\
\text { Ozaki, Inagaki, y } \\
\text { Suzumura, 2000) }\end{array}$ & $\begin{array}{l}\text { Aumento de los receptores } \\
\text { solubles y del factor de ne- } \\
\text { crosis tumoral en personas } \\
\text { de edad avanzada. }\end{array}$ & $\begin{array}{l}(+) \text { TNF-a } \\
(-) \text { IL-1, } \\
(+) I L-1 ß \\
(+/-) \text { IL-6 }\end{array}$ & $\begin{array}{l}\text { El aumento en los niveles de sTNF-R podrá oponerse } \\
\text { a los efectos protectores de TNF por interferir con su } \\
\text { unión al receptor. Esto puede contribuir a la suscepti- } \\
\text { bilidad de los ancianos a enfermedades infecciosas y } \\
\text { neoplásicas. }\end{array}$ \\
\hline $\begin{array}{c}\text { (Bruunsgaard } H_{.}, \\
2000)\end{array}$ & $\begin{array}{l}\text { Alteración en la producción } \\
\text { de citocinas proinflamatorias } \\
\text { como respuesta a la estimu- } \\
\text { lación de lipopolisacáridos } \\
\text { (LPS) en ancianos. }\end{array}$ & $\begin{array}{l}(+) \text { TNF-a } \\
(+) \text { IL-1ß } \\
(+/-) \text { IL-6 }\end{array}$ & $\begin{array}{l}\text { Teniendo en cuenta la disminución en la producción de } \\
\text { TNF-a e IL-1ß después de la exposición a LPS, se pue- } \\
\text { de generar deterioro en la defensa inmune del paciente } \\
\text { de edad avanzada que presente infecciones. }\end{array}$ \\
\hline $\begin{array}{c}\text { (Krakauer y Russo, } \\
\text { 2001) }\end{array}$ & $\begin{array}{l}\text { Niveles de citocinas y an- } \\
\text { ticuerpos en respuesta a la } \\
\text { vacuna de la influenza en } \\
\text { el anciano. }\end{array}$ & $\begin{array}{c}(+/-) \text { IL-6, } \\
(-) \text { IL-10 }\end{array}$ & $\begin{array}{l}\text { No hay correlación entre la concentración en suero de } \\
\text { IL6, IL10 e IFN para producir el anticuerpo. Por su parte, } \\
\text { la IL-10 inhibe citocinas inflamatorias como respuesta } \\
\text { de inmunidad humoral. Se encontró que las vacunas } \\
\text { de virus inactivados son independientes de la concen- } \\
\text { tración sérica de IL6, difiriendo de las vacunas bac- } \\
\text { terianas que necesitan una concentración específica } \\
\text { para generar anticuerpos. }\end{array}$ \\
\hline $\begin{array}{c}\text { (Leng, Chaves, } \\
\text { Koenig, y Walston, } \\
\text { 2002) }\end{array}$ & $\begin{array}{l}\text { La Interleucina } 6 \text { (IL-6) y la } \\
\text { hemoglobina como correla- } \\
\text { ción fisiológica en el síndro- } \\
\text { me de fragilidad geriátrica }\end{array}$ & $(+/-)$ IL-6 & $\begin{array}{l}\text { El aumento de IL- } 6 \text { sérica y la disminución de he- } \\
\text { moglobina se relacionan con las comorbilidades que } \\
\text { presenta el anciano y no con el estado de fragilidad } \\
\text { geriátrica. }\end{array}$ \\
\hline $\begin{array}{c}\text { (Kikuchi, Inagaki, } \\
\text { Shinagawa, y Ueda, } \\
\text { 2004) }\end{array}$ & $\begin{array}{l}\text { Importancia clínica del re- } \\
\text { ceptor de la interleucina } 2 \\
\text { (IL-2) como índice nutri- } \\
\text { cional sistemático positivo } \\
\text { en ancianos }\end{array}$ & (+) IL-2 & $\begin{array}{l}\text { Se asocia el mecanismo inmunológico y la activación de } \\
\text { linfocitos T con el receptor soluble de IL-2, aumentando } \\
\text { la respuesta inflamatoria sistémica. Esta última, altera- } \\
\text { da por las comorbilidades que presentan los pacientes } \\
\text { ancianos, incrementa la susceptibilidad de respuesta a } \\
\text { cualquiera noxa. }\end{array}$ \\
\hline (Cutolo et al., 2006) & $\begin{array}{l}\text { Citocinas séricas y hormonas } \\
\text { esteroideas en la polimialgia } \\
\text { reumática y la artritis reuma- } \\
\text { toide en el adulto mayor. }\end{array}$ & $\begin{array}{l}(+) \text { TNF-a } \\
(+/-) \text { IL-6 }\end{array}$ & $\begin{array}{l}\text { Evaluando las concentraciones de las citocinas en diver- } \\
\text { sas patologías, se observó una respuesta inflamatoria } \\
\text { fuerte con mayor concentración de estas, pero al someter } \\
\text { a los pacientes a tratamiento con glucocorticoides, los } \\
\text { niveles disminuían. }\end{array}$ \\
\hline (Marti et al., 2007) & $\begin{array}{l}\text { Las citocinas y sus patrones } \\
\text { de liberación en pacientes } \\
\text { con inflamación sistémica } \\
\text { y síndrome de respuesta } \\
\text { inflamatoria. }\end{array}$ & $\begin{array}{l}(+) I L-1 ß \\
(+/-) I L-6\end{array}$ & $\begin{array}{l}\text { Correlaciona niveles aumentados de IL- } 6 \text { en sangre, } \\
\text { como predictor positivo para una bacteriemia de mal } \\
\text { pronóstico y un aumento de la estancia hospitalaria } \\
\text { por un síndrome de respuesta inflamatoria sistémica } \\
\text { que puede evolucionar hacia una sepsis complicada o } \\
\text { incluso a un shock séptico. }\end{array}$ \\
\hline (Adamis et al., 2007) & $\begin{array}{l}\text { APOE y citocinas como mar- } \\
\text { cadores biológicos preva- } \\
\text { lentes en la recuperación del } \\
\text { delirio en el adulto mayor. }\end{array}$ & $\begin{array}{c}(-) \text { IL-1, } \\
(+/-) \text { IL-6 }\end{array}$ & $\begin{array}{l}\text { Los niveles aumentados de estos marcadores biológicos } \\
\text { en enfermedad aguda se asocian a la recuperación del } \\
\text { delirio, ya que estas citocinas participan promoviendo el } \\
\text { desarrollo neuronal, la regulación baja del glutamato y la } \\
\text { mejoría funcional del hipocampo. }\end{array}$ \\
\hline
\end{tabular}




\begin{tabular}{|c|c|c|c|}
\hline Autores & Nombre del artículo & Citocina & Resultados \\
\hline (Beloosesky, 2007) & $\begin{array}{l}\text { Citocinas y producción de } \\
\text { Proteína C Reactiva (PRC) } \\
\text { en pacientes de edad avan- } \\
\text { zada y con cirugía por frac- } \\
\text { tura de cadera. }\end{array}$ & $\begin{array}{l}(-) \text { IL-1, } \\
(+/-) \text { IL-6 }\end{array}$ & $\begin{array}{l}\text { Se encontró que la PRC es uno de los indicadores más } \\
\text { importantes en el proceso posquirúrgico; determina el } \\
\text { grado de inflamación e infección y se asocia con inter- } \\
\text { leucinas (IL-1, IL-2) que pueden verse implicadas en } \\
\text { las complicaciones posteriores a la cirugía. }\end{array}$ \\
\hline $\begin{array}{c}\text { (Cederholm et al., } \\
\text { 2007) }\end{array}$ & $\begin{array}{l}\text { Los polimorfismos en genes } \\
\text { de citocinas influyen, a lar- } \\
\text { go plazo, en la superviven- } \\
\text { cia de pacientes ancianos } \\
\text { según su género (masculino } \\
\text { o femenino). }\end{array}$ & $\begin{array}{l}(+) \text { TNF-a } \\
(+) \text { IL-1ß } \\
(+/-) \text { IL-6, } \\
(-) \text { IL-10 }\end{array}$ & $\begin{array}{l}\text { Los alelos antiinflamatorios asociados a IL-6, IL-10, } \\
\text { TNF-a, aumentan la supervivencia en mujeres aproxi- } \\
\text { madamente en tres años. Mientras que los genotipos } \\
\text { asociados a IL- } 13 \text { proinflamatorios disminuyen la su- } \\
\text { pervivencia en tres años en los hombres. }\end{array}$ \\
\hline $\begin{array}{l}\text { (Kilpatrick et al., } \\
\text { 2008) }\end{array}$ & $\begin{array}{l}\text { La homeostasis y el com- } \\
\text { partimento celular de los } \\
\text { linfocitos T CD4+ vírgenes } \\
\text { durante el envejecimiento. }\end{array}$ & IL-7 & $\begin{array}{l}\text { A pesar de la involución del timo, el número de células } \\
\text { T-CD4+ vírgenes disminuye lentamente durante el enve- } \\
\text { jecimiento, sugiriendo un control homeostático periférico } \\
\text { de estas células. Estudios de linfocitos T humanos in vi- } \\
\text { tro, muestran que la IL-7 y otras citocinas pueden esti- } \\
\text { mular la división de estos linfocitos. }\end{array}$ \\
\hline (Lambert C. P., 2008) & $\begin{array}{l}\text { El ejercicio, y no la pérdida } \\
\text { de peso inducida por la die- } \\
\text { ta, disminuye la expresión } \\
\text { de genes inflamatorios en } \\
\text { el músculo esquelético en } \\
\text { ancianos obesos. }\end{array}$ & $\begin{array}{c}(+) \text { TNF-a } \\
(+/-) \text { IL-6, } \\
\text { MGF ARNm }\end{array}$ & $\begin{array}{l}\text { El ejercicio físico disminuyó en un } 50 \% \text { los niveles de } \\
\text { IL-6 y TNF-a mRNA, en cambio, la pérdida de peso no } \\
\text { tuvo ningún efecto. El ejercicio aumentó el MGF ARNm } \\
\text { y demostró efectos positivos sobre los marcadores de } \\
\text { inflamación muscular y el anabolismo en pacientes } \\
\text { ancianos frágiles y en obesos. }\end{array}$ \\
\hline (Kumar A, 2008) & $\begin{array}{l}\text { Resistencia muscular en } \\
\text { ancianos residentes de un } \\
\text { hogar geriátrico, relacionado } \\
\text { con la percepción de fatiga, } \\
\text { la movilidad y el TNF- a circu- } \\
\text { lante, la IL-6 y la proteína de } \\
\text { choque térmico } 70 \text { (Hsp70). }\end{array}$ & $\begin{array}{l}(+) \text { TNF-a } \\
(+/-) \text { IL-6 }\end{array}$ & $\begin{array}{l}\text { En este estudio se analizaron diversos procesos infla- } \\
\text { matorios que implican TNF-a y la interacción entre la } \\
\text { IL-6 y la Hsp70, los cuales potencian la regeneración y } \\
\text { proliferación muscular atenuando el daño. }\end{array}$ \\
\hline (Nicklas et al., 2008) & $\begin{array}{l}\text { El ejercicio físico, la Proteína } \\
\text { C Reactiva (PCR) en plasma } \\
\text { y la interleucina-6 (IL-6) en } \\
\text { personas de edad avanzada. }\end{array}$ & $(+/-)$ IL-6 & $\begin{array}{l}\text { El ejercicio, como estímulo saludable en el ser humano, } \\
\text { permitió comparar marcadores de respuesta y citocinas } \\
\text { como la IL-6, obteniendo un efecto positivo que se ob- } \\
\text { servó en el incremento de la concentración, la resisten- } \\
\text { cia y la energía en el adulto mayor. }\end{array}$ \\
\hline $\begin{array}{l}\text { (A. T. Kumar et al., } \\
\text { 2009) }\end{array}$ & $\begin{array}{l}\text { Perfil de citocinas en pacien- } \\
\text { tes ancianos con sepsis. }\end{array}$ & $\begin{array}{l}(+) \text { TNF-a } \\
(+/-) \text { IL-6 }\end{array}$ & $\begin{array}{l}\text { Estimación en niveles de citocinas TNF-a e IL-6 en pa- } \\
\text { cientes ancianos con sepsis ayudará en la predicción de } \\
\text { la mortalidad. El género femenino fue predictor indepen- } \\
\text { diente mayor de mortalidad en pacientes ancianos que } \\
\text { presentaban un cuadro de sepsis. }\end{array}$ \\
\hline $\begin{array}{l}\text { (Rodhe, Lofgren, } \\
\text { Strindhall, Matussek, } \\
\text { y Molstad, 2009) }\end{array}$ & $\begin{array}{l}\text { Niveles de citocinas en la } \\
\text { orina en adultos mayores } \\
\text { con cistitis aguda y bacte- } \\
\text { riuria asintomática. }\end{array}$ & $\begin{array}{l}(+) \text { TNF-a } \\
(-) \text { IL-1, } \\
(+/-) \text { IL-6, } \\
(-) \text { IL-10, } \\
(+) \text { IL-12 }\end{array}$ & $\begin{array}{l}\text { Concentraciones de citocinas son efectivas para el } \\
\text { diagnóstico de las infecciones urinarias como predic- } \\
\text { tor positivo, ya que estas se aumentan al tener la pato- } \\
\text { logía con su respectiva sintomatología clínica. }\end{array}$ \\
\hline
\end{tabular}




\begin{tabular}{|c|c|c|c|}
\hline Autores & Nombre del artículo & Citocina & Resultados \\
\hline $\begin{array}{c}\text { (Campos Kraychete } \\
\text { D., 2010) }\end{array}$ & $\begin{array}{l}\text { Niveles de citocinas en sue- } \\
\text { ro, en pacientes con dolor } \\
\text { lumbar crónico debido a her- } \\
\text { nias de disco: estudio trans- } \\
\text { versal analítico. }\end{array}$ & $\begin{array}{l}(+) \text { TNF-a } \\
(+/-) \text { IL-6 }\end{array}$ & $\begin{array}{l}\text { Los pacientes con dolor lumbar crónico debido a her- } \\
\text { nias de disco presentan mayores niveles de TNF-alfa y } \\
\text { de IL-6, pero no de IL-1 ni de sTNF-R. }\end{array}$ \\
\hline (Amer M. S, 2010) & $\begin{array}{l}\text { Citocinas proinflamatorias } \\
\text { en adultos mayores egipcios } \\
\text { con enfermedad pulmonar } \\
\text { obstructiva crónica (Epoc). }\end{array}$ & $\begin{array}{l}(+) \text { IL } 1-\beta \\
(+) \text { TNF- } \alpha\end{array}$ & $\begin{array}{l}\text { En pacientes con Epoc se encontraron niveles elevados } \\
\text { de IL1- } \beta \text { y de PCR, asociados al grado de complejidad } \\
\text { de la enfermedad: cuanto más graves los casos, ma- } \\
\text { yores son los niveles de TNF-a y PCR. En pacientes fu- } \\
\text { madores los niveles basales de TNF-a están elevados. }\end{array}$ \\
\hline (Eriksen et al., 2010) & $\begin{array}{l}\text { La expresión de IL- } 6 \text { por os- } \\
\text { teoblastos en personas ma- } \\
\text { yores sanas se ve afectada } \\
\text { por la edad: estimulación, } \\
\text { proliferación y diferenciación. }\end{array}$ & $(+/-)$ IL-6 & $\begin{array}{l}\text { Con la edad los huesos van perdiendo la capacidad de } \\
\text { estimulación, proliferación y diferenciación de osteo- } \\
\text { blastos, lo cual explica la aparición de la osteoporosis, } \\
\text { íntimamente relacionada con el aumento de la IL-6 que } \\
\text { conlleva al deterioro crónico del hueso. }\end{array}$ \\
\hline $\begin{array}{l}\text { (Nagai, Kozaki, } \\
\text { Sonohara, Akishita, } \\
\text { y Toba, 2011) }\end{array}$ & $\begin{array}{l}\text { Relación entre interleu- } \\
\text { cina-6, sustancia blanca } \\
\text { cerebral e hiperintensidad } \\
\text { periventricular en mujeres } \\
\text { de edad avanzada. }\end{array}$ & $(+/-)$ IL-6 & $\begin{array}{l}\text { De acuerdo con los registros de este marcador se } \\
\text { concluye la asociación de IL- } 6 \text { con los criterios de hi- } \\
\text { perintensidad periventricular y de sustancia blanca, } \\
\text { permitiendo un parámetro positivo al estar dicha cito- } \\
\text { cina aumentada. }\end{array}$ \\
\hline $\begin{array}{l}\text { (Kawaguchi, Shiba, } \\
\text { Takano, Maeda, y } \\
\text { Sata, 2011) }\end{array}$ & $\begin{array}{l}\text { Entrenamiento hibrido de } \\
\text { los músculos voluntarios } \\
\text { con contracciones eléctri- } \\
\text { cas en la disminución de } \\
\text { glicemia y niveles de inter- } \\
\text { leucina } 6 \text { (IL-6) en pacientes } \\
\text { de edad avanzada. }\end{array}$ & $(+/-)$ IL-6 & $\begin{array}{l}\text { En la mayoría de casos reportados por pacientes de } \\
\text { edad avanzada, la atrofia muscular se debe al sedenta- } \\
\text { rismo. Al instaurar un entrenamiento hibrido disminu- } \\
\text { ye la glicemia en ayunas explicado por la IL-6, ya que } \\
\text { esta activa la quinasa janus y aumenta la desfosforila- } \\
\text { ción; además participa en la supresión de la transloca- } \\
\text { ción y transcripción del GLUT 4, generando resistencia } \\
\text { a la insulina. }\end{array}$ \\
\hline (Silva et al., 2011) & $\begin{array}{l}\text { Factores clínicos, funciona- } \\
\text { les e inflamatorios asocia- } \\
\text { dos con la fatiga muscular y } \\
\text { fatiga autopercibida en mu- } \\
\text { jeres que residen en una co- } \\
\text { munidad de edad avanzada. }\end{array}$ & $(+/-)$ IL-6 & $\begin{array}{l}\text { Se evaluaron concentraciones plasmáticas de ci- } \\
\text { tocinas inflamatorias con el método de Elisa, el cual } \\
\text { demostró que estas tienen una funcionalidad como } \\
\text { predictor positivo en la fatiga muscular, lo que permi- } \\
\text { te mirar aquellos valores que están aumentados para } \\
\text { orientar el diagnóstico clínico y terapéutico. }\end{array}$ \\
\hline $\begin{array}{c}\text { (Giovannini et al., } \\
2011 \text { ) }\end{array}$ & $\begin{array}{l}\text { La interleucina 6, la Proteína } \\
\text { C Reactiva, el Factor de } \\
\text { Necrosis Tumoral alfa como } \\
\text { predictores de mortalidad } \\
\text { en adultos frágiles y ancia- } \\
\text { nos que viven solos. }\end{array}$ & $(+/-)$ IL-6 & $\begin{array}{l}\text { Es difícil determinar cuál citocina genera la cascada de } \\
\text { inflamación, por lo tanto se sugiere una correlación de } \\
\text { citocinas con comorbilidades propias de los adultos } \\
\text { mayores. Cuando las citocinas se aumentan en la san- } \\
\text { gre potencian una respuesta inmunológica exagerada } \\
\text { que puede, incluso, incrementar la mortalidad en este } \\
\text { tipo de población. }\end{array}$ \\
\hline
\end{tabular}




\begin{tabular}{|c|c|c|c|}
\hline Autores & Nombre del artículo & Citocina & Resultados \\
\hline (Li et al., 2012) & $\begin{array}{l}\text { La IL-6, sus polimorfismos y } \\
\text { la susceptibilidad a la fibrila- } \\
\text { ción auricular en pacientes } \\
\text { chinos mayores que presen- } \\
\text { tan hipertensión arterial. }\end{array}$ & $\begin{array}{l}(+) \text { IL-6 } \\
\text { Inflama- } \\
\text { toria }\end{array}$ & $\begin{array}{l}\text { Este estudio sugiere que los polimorfismos de la IL- } 6 \\
634 \mathrm{C} / \mathrm{G} \text { se asocian con fibrilación auricular; además, } \\
\text { menciona que aquellos pacientes mayores que tie- } \\
\text { nen el alelo G presentan mayor riesgo de padecer } \\
\text { esta enfermedad. }\end{array}$ \\
\hline $\begin{array}{c}\text { (Hernández López J. } \\
\text { C, 2012) }\end{array}$ & $\begin{array}{l}\text { Activación y regulación del } \\
\text { inflamasoma NLRP3 en en- } \\
\text { fermedades infecciosas. }\end{array}$ & $(+) I L-1 \beta$ & $\begin{array}{l}\text { Las citocinas de la familia IL- } 1 \beta \text { se activan por la cas- } \\
\text { pasa- } 1 \text { y, a su vez, por inflamasomas como el NLRP3 } \\
\text { que también se activan por partículas extrañas, mi- } \\
\text { croorganismos o toxinas derivadas de estos. }\end{array}$ \\
\hline (Qian F, 2012) & $\begin{array}{l}\text { Asociación de la edad con la } \\
\text { elevación de TLRs que con- } \\
\text { duce a un incremento de la } \\
\text { respuesta inflamatoria en } \\
\text { ancianos. }\end{array}$ & $\begin{array}{l}\text { (-) IL-8, } \\
\text { TNF-kappa } \\
\text { B, } \\
\text { (+) TNF-a }\end{array}$ & $\begin{array}{l}\text { Los estudios demuestran que las alteraciones en re- } \\
\text { ceptores Toll (TLRs), células dendríticas, monocitos } \\
\text { y macrófagos TLR3 se asocian a una disminución } \\
\text { progresiva de la función del sistema inmune debido } \\
\text { al envejecimiento. }\end{array}$ \\
\hline (Lu et al., 2012) & $\begin{array}{l}\text { Estudio clínico de las célu- } \\
\text { las asesinas NK inducida } \\
\text { por citocinas autólogas para } \\
\text { el tratamiento de pacientes } \\
\text { mayores con linfoma difuso } \\
\text { de células B. }\end{array}$ & $(+) I L-2$ & $\begin{array}{l}\text { Se evaluó la seguridad y la eficacia en un grupo de pa- } \\
\text { cientes mayores con diagnóstico de linfoma difuso de } \\
\text { células } \mathrm{B} \text {, a partir de un tratamiento con NK, produci- } \\
\text { das por el estímulo de citocinas, obteniendo buenos } \\
\text { resultados al reportarse una disminución significativa } \\
\text { de los síntomas. }\end{array}$ \\
\hline (Jozwik et al., 2012) & $\begin{array}{l}\text { Péptidos } \beta \text {-amiloide mejoran } \\
\text { la respuesta proliferativa de } \\
\text { linfocitos T activados (CD4+ } \\
\text { y CD28+) en pacientes con } \\
\text { alzheimer y en pacientes sa- } \\
\text { nos de edad avanzada. }\end{array}$ & $\begin{array}{l}(+) \text { TNF-a } \\
(-) \text { IL-10, } \\
(+/-) \text { IL-6. }\end{array}$ & $\begin{array}{l}\text { En las primeras etapas de la enfermedad de alzheimer } \\
\text { se produce gran cantidad de } \beta \text {-amiloide. La exposición } \\
\text { de linfocitos preestimulados in vitro a péptidos ß-ami- } \\
\text { loides mejora de forma significativa la respuesta pro- } \\
\text { liferativa de estas células, lo que conduce a mayores } \\
\text { niveles de TNF-a, IL-10, IL-6. }\end{array}$ \\
\hline $\begin{array}{c}\text { (McElhaney et al., } \\
\text { 2012) }\end{array}$ & $\begin{array}{l}\text { La necesidad insatisfecha } \\
\text { en el anciano: la inmuno- } \\
\text { senescencia, la infección } \\
\text { crónica por CMV; la comor- } \\
\text { bilidad y la fragilidad son re- } \\
\text { tos para el desarrollo eficaz } \\
\text { de vacunas contra la gripe. }\end{array}$ & $\begin{array}{l}(+) \text { TNF-a } \\
(-) \text { IL-1, } \\
(+/-) \text { IL-6, } \\
(-) \text { IL-10, } \\
(-) \text { TGF- } \beta\end{array}$ & $\begin{array}{l}\text { Cuando una persona envejece se puede registrar el au- } \\
\text { mento de los niveles séricos de citocinas inflamatorias } \\
\text { (TNF-a, IL-1, IL-6). El proceso denominado «inflam- } \\
\text { maging» se ha relacionado con la infección persistente } \\
\text { por citomegalovirus (CMV) y con la senescencia inmu- } \\
\text { ne, mientras que el aumento de citocinas antiinflama- } \\
\text { torias (IL-10, TGF- } \beta \text { ) está posiblemente asociado con } \\
\text { un envejecimiento más saludable. }\end{array}$ \\
\hline (Gomes et al., 2012) & $\begin{array}{l}\text { Efecto del entrenamiento } \\
\text { aeróbico sobre citocinas en } \\
\text { plasma y receptores solu- } \\
\text { bles en las mujeres mayores } \\
\text { con artrosis de rodilla, en } \\
\text { respuesta al ejercicio agudo. }\end{array}$ & $\begin{array}{l}(+/-) \text { IL-6, } \\
(+) \text { TNF-a }\end{array}$ & $\begin{array}{l}\text { Al evaluar los receptores de TNR1 estos aumentaban } \\
\text { de forma significativa, mientras que los TNR2 dismi- } \\
\text { nuían, haciendo una comparación con los pacientes } \\
\text { que se encontraban en reposo. Ello indica que los nive- } \\
\text { les aumentados de estas citocinas los hace más sus- } \\
\text { ceptibles a que la patología empeore. }\end{array}$ \\
\hline (Calvo D, 2012) & $\begin{array}{l}\text { La inflamación crónica a } \\
\text { un año como predictor de } \\
\text { hospitalización y mortalidad } \\
\text { en población adulta mayor. }\end{array}$ & (-) IL-1 & $\begin{array}{l}\text { Los niveles altos de IL-1 se asocian con un estado de } \\
\text { inflamación crónica que es común en los pacientes de } \\
\text { edad avanzada y que están hospitalizados, teniendo } \\
\text { un efecto positivo en cuanto al pronóstico. }\end{array}$ \\
\hline
\end{tabular}




\begin{tabular}{|c|c|c|c|}
\hline Autores & Nombre del artículo & Citocina & Resultados \\
\hline (Rea et al., 2013) & $\begin{array}{l}\text { Receptores asesinos de in- } \\
\text { munoglobulinas (KIR) y sus } \\
\text { halogrupos A y B; junto con } \\
\text { células asesinas naturales y } \\
\text { perfil de citocinas en sujetos } \\
\text { de edad avanzada: observa- } \\
\text { ción de Octo/nanogenarios } \\
\text { en el estudio (Belfast). }\end{array}$ & $\begin{array}{l}(+) \text { IL-12, } \\
(+/-) \text { IL-6, } \\
(-) \text { IL-10, } \\
(-) \text { TGF- } \beta \text {, } \\
(+) \text { TNF-a }\end{array}$ & $\begin{array}{l}\text { Los pacientes ancianos con haplotipo KIR-A mostra- } \\
\text { ron mayor número de células NK en comparación con } \\
\text { los de haplotipo KIR-B. Por el contrario, los portadores } \\
\text { de KIR-B evidenciaron una tendencia mayor de citoci- } \\
\text { nas inflamatorias en suero comparadas con los porta- } \\
\text { dores KIR-A. }\end{array}$ \\
\hline $\begin{array}{c}\text { (Westhoff et al., } \\
\text { 2013) }\end{array}$ & $\begin{array}{l}\text { Niveles de citocinas preope- } \\
\text { ratorias en líquido cefalo- } \\
\text { rraquídeo y riesgo de delirio } \\
\text { posoperatorio en pacien- } \\
\text { tes ancianos con fractura } \\
\text { de cadera. }\end{array}$ & $\begin{array}{c}(-) \text { IL-1, } \\
(+/-) \text { IL-6, } \\
(+) \text { IL-15 }\end{array}$ & $\begin{array}{l}\text { Los resultados se ajustan a la hipótesis. El delirio pos- } \\
\text { quirúrgico es una respuesta neuroinflamatoria disfun- } \\
\text { cional que puede ser consecuencia de una reducción } \\
\text { de los mediadores antiinflamatorios y, no exclusiva- } \\
\text { mente, debido a un exceso de citocinas proinflamato- } \\
\text { rias, ya que el cerebro no está expuesto solamente a } \\
\text { citocinas inflamatorias. }\end{array}$ \\
\hline (Pereira et al., 2013) & $\begin{array}{l}\text { El efecto del ejercicio físi- } \\
\text { co y los polimorfismos en } \\
\text { TNF-a, IL-6 e IL-10, en la } \\
\text { respuesta inflamatoria y el } \\
\text { rendimiento físico de muje- } \\
\text { res mayores. }\end{array}$ & $\begin{array}{l}(+) \text { TNF-a } \\
(+/-) \text { IL-6 } \\
(-) \text { IL-10. }\end{array}$ & $\begin{array}{l}\text { Se evaluó la interacción entre SNP rs } 1800629 \text { en el } \\
\text { TNF-a, rs1800795, en la IL-6 y rs } 1800896 \text { en IL10. } \\
\text { La combinación de genotipos asociados con un per- } \\
\text { fil antiinflamatorio (TNF-a bajo e IL-6, IL-10 de alta } \\
\text { producción) muestra mejoría en el rendimiento físico } \\
\text { y en la capacidad para realizar actividades cotidianas. } \\
\text { Factores genéticos y ambientales, con la práctica de } \\
\text { ejercicio físico, contribuyeron a la mejora de la capaci- } \\
\text { dad funcional en las mujeres parte del estudio. }\end{array}$ \\
\hline $\begin{array}{c}\text { (Lechner et al., } \\
\text { 2013) }\end{array}$ & $\begin{array}{l}\text { Respuesta de citocinas y } \\
\text { quimiocinas a parásitos (hel- } \\
\text { mintos y protozoarios), hon- } \\
\text { gos, ácaros y alérgenos en } \\
\text { recién nacidos, niños, adul- } \\
\text { tos y ancianos. }\end{array}$ & $\begin{array}{l}(+) \text { TNF-a } \\
(+/-) \text { IL-6, } \\
\text { IL-19, } \\
\text { IL-27, } \\
\text { IL-33. }\end{array}$ & $\begin{array}{l}\text { Infecciones por helmintos y protozoarios activan en } \\
\text { adultos citocinas Th2, en particular, IL-27. Ante la ex- } \\
\text { posición repetida a parásitos intestinales, genera un } \\
\text { repertorio de respuestas inmunes con citocinas regu- } \\
\text { ladoras y quimiocinas para controlar la infección por } \\
\text { parásitos, previniendo un excesivo daño orgánico. }\end{array}$ \\
\hline $\begin{array}{c}\text { (Moro-García et al., } \\
\text { 2013) }\end{array}$ & $\begin{array}{l}\text { La suplementación oral con } \\
\text { lactobacillus delbrueckii subp. } \\
\text { bulgaricus } 8481 \text { potencia el } \\
\text { sistema inmune en sujetos } \\
\text { de edad avanzada. }\end{array}$ & $\begin{array}{c}(+) \text { IFN-y, } \\
(+) \text { IL-1 } \beta, \\
(+) \text { IL-2, } \\
(-) \text { IL-4, } \\
(-) \text { IL-5, } \\
(+/-) \text { IL-6, } \\
(-) \text { IL-8, } \\
(-) \text { IL-10, } \\
(+) I L-12 \\
\text { p70, } \\
(+) \text { TNF- } \alpha \\
(+) \text { TNF- } \beta\end{array}$ & $\begin{array}{l}\text { Tras seis meses de suplementación dietética con lac- } \\
\text { tobacillus delbrueckii subsp. bulgaricus } 8481 \text {, aumentó } \\
\text { el porcentaje de células NK; mejoraron los parámetros } \\
\text { que definen el perfil de riesgo inmunológico y el retardo } \\
\text { del envejecimiento de linfocitos T, aumentando el nú- } \\
\text { mero de células T inmaduras. También disminuyeron } \\
\text { los niveles de IL-8, pero aumentó el péptido antimicro- } \\
\text { biano HBD-2. Tras detener la ingesta de probióticos, } \\
\text { disminuyeron también los efectos. }\end{array}$ \\
\hline
\end{tabular}




\begin{tabular}{|c|c|c|c|}
\hline Autores & Nombre del artículo & Citocina & Resultados \\
\hline (Honma et al., 2013) & $\begin{array}{l}\text { Aumento inflamatorio de la } \\
\text { interleucina-1ß y la inter- } \\
\text { leucina- } 6 \text { sistémica durante } \\
\text { la fase de agitación como } \\
\text { predictores de la enferme- } \\
\text { dad de alzheimer. }\end{array}$ & $\begin{array}{l}(+) I L-1 ß \\
(+/-) I L-6\end{array}$ & $\begin{array}{l}\text { Se concluyó que las interleucinas IL-1ß, IL-6, asociadas } \\
\text { a factores de riesgo, pueden desarrollar enfermedad de } \\
\text { alzheimer, principalmente durante la fase de agitación. } \\
\text { Sin embargo, no se relaciona con demencia vascular. }\end{array}$ \\
\hline (Neville et al., 2013) & $\begin{array}{l}\text { Las proteínas flagelina proin- } \\
\text { flamatorias de las bacterias } \\
\text { comensales móviles pre- } \\
\text { valentes son variablemente } \\
\text { abundantes en el microbio- } \\
\text { ma intestinal en personas de } \\
\text { edad avanzada. }\end{array}$ & $(-)$ IL-8 & $\begin{array}{l}\text { IL-8 juega un papel importante al ser estimulada por la } \\
\text { proteína flagelina; ella permite analizar una mejor es- } \\
\text { tructuración de rutas bioquímicas complejas y, a la vez, } \\
\text { completas para las especies. }\end{array}$ \\
\hline $\begin{array}{c}\text { (Verschoor et al., } \\
\text { 2014) }\end{array}$ & $\begin{array}{l}\text { Asociación entre las alte- } \\
\text { raciones, en función y can- } \\
\text { tidad, de los monocitos en } \\
\text { sangre periférica con las } \\
\text { enfermedades crónicas en } \\
\text { pacientes de edad avanzada } \\
\text { con fragilidad. }\end{array}$ & $(+)$ TNF-a & $\begin{array}{l}\text { Pacientes de edad avanzada y adultos frágiles tie- } \\
\text { nen mayor producción de TNF que los adultos sanos. } \\
\text { La cantidad de los monocitos se altera en la vejez y } \\
\text { en ciertas enfermedades crónicas. Los monocitos } \\
\text { CX }{ }_{3} \text { CR1 están asociados con la demencia. }\end{array}$ \\
\hline $\begin{array}{c}\text { (Sudheimer et al., } \\
\text { 2014) }\end{array}$ & $\begin{array}{l}\text { Interacción de cortisol y ci- } \\
\text { tocinas en el volumen del } \\
\text { hipocampo en el anciano. }\end{array}$ & $\begin{array}{l}(+) \text { TNF-a } \\
(+) \text { IL-1 } \beta \\
(+/-) \text { IL-6, } \\
(-) \text { IL-8, } \\
(-) \text { IL-10, } \\
(+) \text { IL-12, }\end{array}$ & $\begin{array}{l}\text { Niveles vespertinos elevados de cortisol junto a con- } \\
\text { centraciones altas de IL- } 6 \text { y TNF- a se asocian con vo- } \\
\text { lúmenes más pequeños del hipocampo en los adultos } \\
\text { mayores. También ocurre de manera independiente } \\
\text { con niveles elevados de cortisol. }\end{array}$ \\
\hline $\begin{array}{c}\text { (Uchida Y. et al., } \\
\text { 2014) }\end{array}$ & $\begin{array}{l}\text { La asociación entre la de- } \\
\text { ficiencia auditiva y los po- } \\
\text { limorfismos de los genes } \\
\text { que codifican mediadores } \\
\text { inflamatorios en población } \\
\text { envejecida japonesa. }\end{array}$ & $(+)$ TNF-a & $\begin{array}{l}\text { Este estudio de cohortes demostró que TNF- a y } \\
\text { rs } 180063 \text { TNFRS F1B rs1061624 contribuyen a un } \\
\text { riesgo de discapacidad auditiva en personas mayo- } \\
\text { res. El TNF-a y las interacciones con sus receptores } \\
\text { juegan un papel fundamental en la patogénesis de la } \\
\text { respuesta inflamatoria; también causan la muerte y } \\
\text { proliferación celular programada. Las cascadas de se- } \\
\text { ñalización de TNF-a están involucradas en el envejeci- } \\
\text { miento del oído. }\end{array}$ \\
\hline (Hibberd et al., 2014) & $\begin{array}{l}\text { No hay evidencia de daño } \\
\text { con la ingesta de cultivos } \\
\text { probióticos de lactobacillus } \\
\text { rhamnosus GG ATCC } 53103 \\
\text { en adultos mayores sanos. } \\
\text { Estudio abierto en Fase } 1 \\
\text { para valorar la seguridad, la } \\
\text { tolerancia y la respuesta de } \\
\text { las citocinas. }\end{array}$ & $\begin{array}{l}(-) \text { IL-8, } \\
(-) \text { IL-13. }\end{array}$ & $\begin{array}{l}\text { El lactobacillus rhamnosus GG ATCC } 53103 \text { (LGG) es } \\
\text { seguro y bien tolerado por adultos sanos de } 65 \text { años } \\
\text { o mayores. Este ensayo clínico evaluó la seguridad y } \\
\text { tolerabilidad de colonias (UFC) de LGG administrados } \\
\text { por vía oral. También observó efectos de LGG en el } \\
\text { microbioma intestinal y en niveles en plasma de ci- } \\
\text { tocinas inmunes. No se detectaron eventos adversos } \\
\text { graves. Los niveles de la citocina proinflamatoria IL-8 } \\
\text { disminuyeron durante el consumo de LGG, volviendo } \\
\text { hacia la línea base un mes después de suspenderlo. }\end{array}$ \\
\hline
\end{tabular}




\begin{tabular}{|c|c|c|c|}
\hline Autores & Nombre del artículo & Citocina & Resultados \\
\hline $\begin{array}{c}\text { (Beenakker et al., } \\
\text { 2014) }\end{array}$ & $\begin{array}{l}\text { Variantes del gen de la IL-10 } \\
\text { asociada a la fuerza muscu- } \\
\text { lar en una población de per- } \\
\text { sonas mayores en África: un } \\
\text { gen candidato a estudiar. }\end{array}$ & $\begin{array}{l}(+) \text { TNF-a } \\
(-) \text { IL-10, }\end{array}$ & $\begin{array}{l}\text { En zonas rurales de Ghana se encontraron más varian- } \\
\text { tes genéticas del gen de IL-10, asociadas con diferen- } \\
\text { tes capacidades de producción de IL-10 y TNF-a en } \\
\text { comparación con poblaciones caucásicas. Se observó } \\
\text { que variantes del gen de IL-10 generan una respuesta } \\
\text { de citocinas proinflamatorias asociadas a una mayor } \\
\text { fuerza muscular, mientras que los que generan una } \\
\text { respuesta antiinflamatoria están asociados a menor } \\
\text { fuerza muscular. }\end{array}$ \\
\hline $\begin{array}{c}\text { (Garofolo, Ferreira, } \\
\text { y Miranda Junior, } \\
\text { 2014) }\end{array}$ & $\begin{array}{l}\text { Los biomarcadores de infla- } \\
\text { mación pueden ser de utili- } \\
\text { dad para la identificación de } \\
\text { la enfermedad arterial oclu- } \\
\text { siva periférica avanzada. }\end{array}$ & $(+/-)$ IL-6. & $\begin{array}{l}\text { Los niveles de PCR y de IL-6 elevados en personas } \\
\text { con enfermedad arterial oclusiva periférica avanzada } \\
\text { sugieren que los biomarcadores de inflamación indi- } \\
\text { can una enfermedad más grave. Se necesitan estudios } \\
\text { prospectivos para comprobar esta hipótesis. }\end{array}$ \\
\hline (Gentile et al., 2014) & $\begin{array}{l}\text { Inmunidad protectora y de- } \\
\text { fectos en la respuesta in- } \\
\text { mune neonatal y en la edad } \\
\text { avanzada frente a la sepsis. }\end{array}$ & $\begin{array}{l}(-) \text { IL-10, } \\
(+/-) \text { IL-6, } \\
\text { (+) TNF }\end{array}$ & $\begin{array}{l}\text { El envejecimiento tiene un impacto profundo en la inmu- } \\
\text { nidad innata; genera un estado proinflamatorio crónico, } \\
\text { así como una predilección hacia mielopoyesis. En ratas } \\
\text { de edad avanzada se observó una respuesta disfuncio- } \\
\text { nal frente a la sepsis; respuesta inflamatoria innata ate- } \\
\text { nuada; inflamación sistémica continua y una supresión } \\
\text { inmune adaptativa, con la incapacidad de volver hacia la } \\
\text { homeostasis basal. }\end{array}$ \\
\hline (Arisi, 2014) & $\begin{array}{l}\text { Señales y conexiones del } \\
\text { sistema nervioso e inmu- } \\
\text { nológico: las citocinas en } \\
\text { la fisiología y la patología } \\
\text { del hipocampo. }\end{array}$ & $\begin{array}{l}(+) \text { IL-1 } \\
(-) \text { IL-10, } \\
(+) \text { IFN-y. }\end{array}$ & $\begin{array}{l}\text { La IL-1 } \beta \text { es necesaria para adquirir nueva información, } \\
\text { potenciar la memoria y almacenarla en el hipocampo. } \\
\text { La IL-6 tiene un papel regulador negativo en la adqui- } \\
\text { sición de memoria a largo plazo. En pacientes con epi- } \\
\text { lepsia del lóbulo temporal se observó incremento en } \\
\text { las concentraciones de IL-10, IFN- }- \text {, ICAM1, CCL2; y } \\
\text { CCl4 a nivel del hipocampo. }\end{array}$ \\
\hline (Wong et al., 2014) & $\begin{array}{l}\text { La infección por virus sincitial } \\
\text { respiratorio (VRS) en ratones } \\
\text { de edad avanzada resulta en } \\
\text { la expresión alterada de ge- } \\
\text { nes antivirales y empeora- } \\
\text { miento de la enfermedad. }\end{array}$ & $\begin{array}{l}(+) \text { IFN- } y, \\
(-) \text { IL-4, } \\
(-) \text { IL-10, } \\
(+) \text { MCP-1, } \\
(+/-) \text { IL-6, } \\
(+) \text { TNF-a } \\
(+) \text { IL-1 } \beta \\
(+) \text { OPN. }\end{array}$ & $\begin{array}{l}\text { Las personas mayores son más susceptibles a la } \\
\text { neumonía por VRS. Se utilizó un modelo de ratas con } \\
\text { neumonía producida por VRS para examinar cómo el } \\
\text { envejecimiento altera la patología pulmonar, modula las } \\
\text { expresiones de genes antivirales y la producción de ci- } \\
\text { tocinas. La expresión de genes antivirales, incluyendo } \\
\text { citocinas proinflamatorias IL-1 y OPN, se altera por la } \\
\text { edad. A mayor edad, menor cinética y magnitud de ex- } \\
\text { presión génica antiviral. Hay diferencias inherentes en } \\
\text { respuesta a la infección por VRS en ratas según la edad. }\end{array}$ \\
\hline $\begin{array}{c}\text { (J. Kumar et al., } \\
\text { 2014) }\end{array}$ & $\begin{array}{l}\text { Contaminantes orgánicos } \\
\text { persistentes y marcadores } \\
\text { inflamatorios en un estu- } \\
\text { dio transversal con adultos } \\
\text { mayores suecos: cohorte } \\
\text { El Pivus. }\end{array}$ & $(+/-)$ IL-6. & $\begin{array}{l}\text { Se analizó el papel de los diferentes marcadores infla- } \\
\text { matorios en relación con los diversos contaminantes, } \\
\text { concluyéndose que las citocinas no tienen significado } \\
\text { estadístico para predecir la asociación con los diferen- } \\
\text { tes plaguicidas planteados en el estudio. }\end{array}$ \\
\hline
\end{tabular}




\begin{tabular}{|c|c|c|c|}
\hline Autores & Nombre del artículo & Citocina & Resultados \\
\hline $\begin{array}{c}\text { (Beltran Valls et al., } \\
\text { 2014) }\end{array}$ & $\begin{array}{l}\text { El entrenamiento muscular } \\
\text { de tipo explosivo con resis- } \\
\text { tencia moderada induce una } \\
\text { mejor respuesta funcional } \\
\text { de tipo cardiovascular y me- } \\
\text { jores adaptaciones molecu- } \\
\text { lares en adultos mayores. }\end{array}$ & $\begin{array}{l}(-) \text { IL-4 } \\
(+/-) \text { IL-6 } \\
(-) \text { IL-13 } \\
(+) \text { IL-15 } \\
(+) \text { TNFa } \\
(+) \text { MIP-1b }\end{array}$ & $\begin{array}{l}\text { Realizar un entrenamiento muscular de tipo explosivo } \\
\text { con frecuencia e intensidad moderada durante } 12 \text { se- } \\
\text { manas, mejoró significativamente la fuerza muscular, } \\
\text { potencia y rendimiento funcional en sujetos de edad } \\
\text { avanzada, sin causar modificaciones perjudiciales en } \\
\text { parámetros inflamatorios o cardiovasculares. Además, } \\
\text { mostraron mejoría cardiovascular, mejor respuesta in- } \\
\text { flamatoria a nivel sistémico y celular mediante la mo- } \\
\text { dulación de marcadores antioxidantes inducidos por el } \\
\text { estrés como la mieloperoxidasa (MPO), la proteína de } \\
\text { choque térmico } 70 \text { (Hsp70) y } 27 \text { (Hsp27) y la tiorredo- } \\
\text { xina reductasa } 1 \text { (TrXR1). }\end{array}$ \\
\hline (Jia et al., 2014) & $\begin{array}{l}\text { Cirugías de corta duración } \\
\text { disminuyen la incidencia } \\
\text { de delirio posoperatorio y } \\
\text { otras complicaciones en } \\
\text { pacientes ancianos con } \\
\text { carcinoma colorrectal. }\end{array}$ & $\begin{array}{l}(+) \text { TNF-a } \\
(-) \text { IL-1, } \\
(+/-) \text { IL-6, } \\
(-) \text { IL-8 }\end{array}$ & $\begin{array}{l}\text { Los pacientes con cirugías de corta duración para cán- } \\
\text { cer colorrectal presentan con menor frecuencia delirio } \\
\text { posoperatorio, debido a la reducción de la respuesta } \\
\text { inflamatoria sistémica mediada por la IL-6. }\end{array}$ \\
\hline (Tu et al., 2014) & $\begin{array}{l}\text { Interleucina } 1 \text { B C511T, po- } \\
\text { limorfismo funcional que } \\
\text { modula la conectividad de } \\
\text { la media corteza cingulada } \\
\text { anterior en varones mayores } \\
\text { sin demencia. }\end{array}$ & 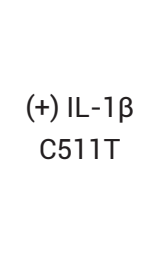 & $\begin{array}{l}\text { Los pacientes de edad avanzada con alteraciones cog- } \\
\text { nitivas podrían explicarse a través de estas variacio- } \\
\text { nes genéticas. Pacientes portadores de polimorfismo } \\
\text { IL- } 1 \beta \text { T/T tendrán un empeoramiento progresivo en su } \\
\text { cuadro de demencia. }\end{array}$ \\
\hline (Sapey E et al., 2014) & $\begin{array}{l}\text { La inhibición de la phosphoi- } \\
\text { nositil 3-quinasa restaura la } \\
\text { eficacia de los neutrófilos } \\
\text { en los ancianos: tratamien- } \\
\text { to dirigido para el manejo de } \\
\text { la inmunosenescencia. }\end{array}$ & $(+)$ TNF-a & $\begin{array}{l}\text { Se evidencio el aumento de la actividad de la proteina- } \\
\text { sa de neutrófilos en los adultos mayores, asociado con } \\
\text { un aumento de la inflamación sistémica. La migración } \\
\text { inexacta fue causalmente vinculada con un aumento } \\
\text { de la PI3K. En donantes mayores se demostró mayor } \\
\text { actividad de PI3K, en comparación con células de do- } \\
\text { nantes jóvenes. Inhibir la PI3K puede ofrecer una nue- } \\
\text { va estrategia para reducir la inflamación inapropiada } \\
\text { en pacientes mayores. }\end{array}$ \\
\hline (Krug et al., 2015) & $\begin{array}{l}\text { Respuesta inflamatoria en } \\
\text { pacientes con asma indu- } \\
\text { cidas por alérgenos mo- } \\
\text { dificadas por un ADNzima } \\
\text { GATA3 específica. }\end{array}$ & $\begin{array}{l}(-) \text { IL-4, } \\
(-) \text { IL-5, } \\
(-) \text { IL-13. }\end{array}$ & $\begin{array}{l}\text { La sobreexpresión del GATA3 se ha observado en pa- } \\
\text { cientes con asma grave. Desarrollando una enzima } \\
\text { ADN-GATA3 (ADNzimas), la hgd40 ADNzima ha de- } \\
\text { mostrado eficacia en modelos preclínicos de inflama- } \\
\text { ción alérgica de las vías respiratorias y ha reducido } \\
\text { significativamente los niveles de mRNA de GATA3 y de } \\
\text { citocinas Th2 en los linfocitos T. Hasta ahora, no se ha } \\
\text { encontrado efectos secundarios ni problemas de se- } \\
\text { guridad en tres ensayos aleatorizados controlados con } \\
\text { placebo. Actualmente, estos estudios se encuentran } \\
\text { en la fase } 2 \text {. }\end{array}$ \\
\hline
\end{tabular}




\begin{tabular}{|c|c|c|c|}
\hline Autores & Nombre del artículo & Citocina & Resultados \\
\hline (Baierle et al., 2015) & $\begin{array}{l}\text { Relación entre la inflama- } \\
\text { ción, el estrés oxidativo y el } \\
\text { deterioro cognitivo en an- } \\
\text { cianos institucionalizados }\end{array}$ & $\begin{array}{l}(+) \text { IL-1 } \beta \\
(-) \text { IL-6, } \\
(-) \text { IL-10, } \\
(+) \text { TNF-a, } \\
(+) \text { IFN- } \gamma \text {. }\end{array}$ & $\begin{array}{l}\text { Se demostró un incremento de estrés oxidativo y altos } \\
\text { niveles de citocinas proinflamatorias en el grupo de per- } \\
\text { sonas mayores institucionalizadas. Niveles elevados de } \\
\text { marcadores inflamatorios se correlacionan con mayor } \\
\text { estrés oxidativo y ambos se asociaron con bajo rendi- } \\
\text { miento cognitivo. Los hallazgos sugieren que individuos } \\
\text { con un menor estado antioxidante son más vulnerables } \\
\text { al estrés oxidativo, que se asocia con la función cogniti- } \\
\text { va; reduciendo la esperanza y calidad de vida. }\end{array}$ \\
\hline $\begin{array}{c}\text { (Rajbhoj, Shete, } \\
\text { Verma, y Bhogal, } \\
2015)\end{array}$ & $\begin{array}{l}\text { Efecto del yoga en cito- } \\
\text { cinas proinflamatorias y } \\
\text { antiinflamatorios en traba- } \\
\text { jadores de la industria de } \\
\text { Lonavla: un ensayo clínico } \\
\text { controlado aleatorizado. }\end{array}$ & $\begin{array}{c}(+) \text { IL-1 } \beta, \\
(-) \text { IL-10 }\end{array}$ & $\begin{array}{l}\text { El estudio demostró que la práctica del yoga podría re- } \\
\text { ducir la citocina proinflamatoria y aumentar la citocina } \\
\text { antiinflamatoria; además, hay una disminución signifi- } \\
\text { cativa en IL-1 } \beta \text { y el aumento notable de IL-10. }\end{array}$ \\
\hline
\end{tabular}

Fuente: elaboración propia e información adaptada de la bibliografía.

*(+): Proinflamatorio / *(-): Antiinflamatorio.

Luego se realizó la tabla «Clasificación de las citocinas» (Tabla 2) donde se indica la clasificación de los cinco principales grupos de citocinas que se abordan en la revisión temática.

Tabla 2. Clasificación de las citocinas.

\begin{tabular}{|l|l|}
\hline \multicolumn{1}{|c|}{ Grupo } & \multicolumn{1}{|c|}{ Citocina } \\
\hline $\begin{array}{l}\text { Factores de diferenciación celular (TGF): influyen en la diferenciación de } \\
\text { células hematopoyéticas. }\end{array}$ & TGF $\beta$, PDGF, bFGF, OPN, IGF-1, MGF. \\
\hline $\begin{array}{l}\text { Factores estimuladores de colonias (FSC): tienen la capacidad selectiva de } \\
\text { inducir la diferenciación de células inmaduras. }\end{array}$ & GM-CSF, G-CSF, LIF, MCP-1, MIP-1b \\
\hline $\begin{array}{l}\text { Factores de necrosis tumoral (TNF): Ilamados así por su acción necrótica } \\
\text { sobre tumores. }\end{array}$ & TNF a, TNF- $\beta$, TNF-kappa B \\
\hline $\begin{array}{l}\text { Interleucinas (ILs): son las citocinas que mayor efecto tienen en el sistema } \\
\text { inmune; estas moléculas actúan como señal de comunicación entre dis- } \\
\text { tintos tipos de leucocitos. }\end{array}$ & $\begin{array}{l}\text { IL-1, IL- } \beta, \text { IL-2, IL-4, IL-5, IL-6, IL-8, IL-10, IL- } \\
\text { 13, IL-15, IL-19, IL-27, IL-33. }\end{array}$ \\
\hline $\begin{array}{l}\text { Interferones (IFN): glucoproteínas que interfieren en la replicación de virus. } \\
\text { IFN- }-\gamma\end{array}$ & \\
\hline
\end{tabular}

Fuente: elaboración propia e información adaptada de Lopera D., Gómez L. M., Cano L. E., Aristizábal B., Anaya J. M., Rojas W. (2012). Inmunología de Rojas 16a edición. Medellín: CIB Fondo editorial, capítulo 14, 209-229.

Finalmente, se desarrolló la tabla «Citocinas mediadoras de inflamación» (Tabla 3), clasificando las citocinas implicadas en el proceso inflamatorio y sus mediadores primarios definidos como citocinas proinflamatorias y las antiinflamatorias con sus principales funciones. Así entonces, el lector tendrá una mejor comprensión del desempeño de estas en la salud o enfermedad del adulto mayor. 
Tabla 3. Citocinas mediadoras de inflamación.

\begin{tabular}{|c|c|c|}
\hline \multicolumn{2}{|c|}{ Citocina } & \multirow{2}{*}{$\begin{array}{l}\text { Función } \\
\text { Coestimulación de células presentadoras de antígenos (CPA) y células T; inflamación y } \\
\text { fiebre; respuesta de fase aguda; hematopoyesis. }\end{array}$} \\
\hline \multirow{11}{*}{ Proinflamatoria } & IL-1B & \\
\hline & IL-2 & Induce la proliferación de células B, células T activadas y función de células NK. \\
\hline & IL-6 & $\begin{array}{l}\text { Respuesta de fase aguda; proliferación de células B; trombopoyesis. Induce la diferen- } \\
\text { ciación de eosinófilos y la producción de inmunoglubulina A. }\end{array}$ \\
\hline & IL-12 & $\begin{array}{l}\text { Estimula proliferación de células NK, producción de INF-Y; promueve las funciones de } \\
\text { la inmunidad celular. }\end{array}$ \\
\hline & IL-15 & Induce la producción de las células NK. \\
\hline & OPN o Eta- 1 & $\begin{array}{l}\text { Proteína que participa en mineralización ósea, adherencia celular, migración celular, en- } \\
\text { fermedad inflamatoria crónica y la transformación. }\end{array}$ \\
\hline & IFN-Y & $\begin{array}{l}\text { Induce MHC I (complejo mayor de histocompatibilidad) en células somáticas y MHC II } \\
\text { en CPA; activa macrófagos, neutrófilos, células NK; promueve la inmunidad mediada } \\
\text { por células; posee efectos antivirales. Es quimiotáctico para monocitos. }\end{array}$ \\
\hline & MCP-1 & $\begin{array}{l}\text { Induce la expresión de las integrinas requeridas para la quimiotáxis; actúa sobre mono- } \\
\text { citos, linfocitos T de memoria, basófilos y células NK; induce la liberación de gránulos } \\
\text { por linfocitos T CD8+ y es un potente inductor de la liberación de histamina por los } \\
\text { basófilos. }\end{array}$ \\
\hline & MIP-1b & $\begin{array}{l}\text { Proteína inflamatoria de macrófagos, quimioquina crucial en la respuesta inmune a la } \\
\text { inflamación e infección. }\end{array}$ \\
\hline & TNF-a & $\begin{array}{l}\text { Agente antitumoral, neovascularizante y estimulante de la resorción ósea. Induce a } \\
\text { la expresión de otros factores de crecimiento autocrinos; incrementa la respuesta } \\
\text { celular a los factores de crecimiento e induce vías de señalización que llevan a la } \\
\text { proliferación celular. }\end{array}$ \\
\hline & TNF- $\boldsymbol{\beta}$ & Agente antitumoral, neovascularizante y estimulante de la resorción ósea. \\
\hline \multirow{8}{*}{ Antiinflamatoria } & IL-1 & $\begin{array}{l}\text { Coestimulación de CPA y células } \mathrm{T} \text {; inflamación y fiebre; respuesta de fase aguda; he- } \\
\text { matopoyesis. }\end{array}$ \\
\hline & IL-4 & $\begin{array}{l}\text { Induce la proliferación, función y crecimiento del mastocito y de la célula hematopoye- } \\
\text { tica pluripotencial. }\end{array}$ \\
\hline & IL-5 & Actúa en la función y crecimiento de eosinófilos. \\
\hline & IL-6 & $\begin{array}{l}\text { Respuesta de fase aguda; proliferación de células B; trombopoyesis. Induce la diferen- } \\
\text { ciación de eosinófilos y la producción de inmunoglobulina A. }\end{array}$ \\
\hline & IL-8 & Quimiotáxis de neutrófilos y células T. \\
\hline & IL-10 & $\begin{array}{l}\text { Inhibe la producción de citocinas; promueve la proliferación de células B y de anticuer- } \\
\text { pos; suprime la inmunidad celular y produce el crecimiento de mastocitos. }\end{array}$ \\
\hline & IL-13 & $\begin{array}{l}\text { Inhibe la producción de citocinas inflamatorias de macrófagos; promueve el crecimien- } \\
\text { to y la proliferación de células } B \text {. }\end{array}$ \\
\hline & TGF- $\beta$ & $\begin{array}{l}\text { Inhibe la producción de citocinas y la proliferación de macrófagos y linfocitos; promue- } \\
\text { ve la reparación de heridas. Posee un efecto angiogénico e interviene en el desarrollo } \\
\text { tumoral, estimulando la proliferación celular e induciendo la angiogénesis tumoral. }\end{array}$ \\
\hline
\end{tabular}

Fuente: elaboración propia e información adaptada de Lopera D., Gómez L. M., Cano L. E., Aristizábal B., Anaya J. M., Rojas W. (2012). Inmunología de Rojas 16ª edición. Medellín: CIB Fondo editorial, capítulo 14, 209-229. 


\section{Discusión}

Al revisar los temas más investigados se encontraron hallazgos que sustentan la idea de una inflamación persistente y los mecanismos de adaptación que evitan el deterioro de órganos y tejidos donde actúan citocinas como IL-1 $\beta$, IL-6 y TNF-a. En edades avanzadas la respuesta inflamatoria disminuye, aumentando la incidencia de procesos infecciosos. Ante ello, el ejercicio y la dieta tienen efectos positivos, mejorando el rendimiento físico, fortaleciendo el sistema inmune y favoreciendo la sintomatología derivada de enfermedades óseas y articulares. La genética asume un rol importante en la presentación de citocinas y de células asesinas naturales que intervienen en el sistema inmune.

Por otra parte, enfermedades como el alzheimer, el delirio y los trastornos neuropsiquiátricos están mediados por altos niveles de citocinas proinflamatorias; además se halla una alteración de aquellas que renuevan el tejido pulmonar lesionado y los polimorfismos determinan mayor o menor supervivencia con respecto a determinadas patologías. En consecuencia, la medición seriada de las concentraciones séricas de interleucinas como IL-6 podría tener un valor predictivo del pronóstico de diagnósticos, tratamientos y exploraciones complementarias más exhaustivas.

Los resultados evidencian que la respuesta inflamatoria es una compleja serie de acontecimientos adaptativos en los que intervienen los sistemas neuroendocrino, metabólico e inmunológico. Distintos estudios afirman que la prevalencia de las infecciones aumenta con la edad debido a la disminución de la respuesta inmune asociada al envejecimiento (Qian F., 2012). En el tracto digestivo de adultos ma- yores se encuentra aumentada una proteína bacteriana proinflamatoria llamada flagelina (Neville et al., 2013); otra infección persistente y crónica es la causada por el citomegalovirus, el cual produce citocinas proinflamatorias como respuesta a la inmunosenescencia, alteraciones de interleucinas IL-8, NF-kappa B, TNF-a y a los receptores Toll TLRs; mientras que el incremento de citocinas antiinflamatorias IL-10, TGF- $\beta$ permiten un envejecimiento más saludable (McElhaney et al., 2012). Por lo tanto, al inhibir las enzimas encargadas de aumentar la respuesta inflamatoria, se restaura el número de neutrófilos (Sapey E. et al., 2014) disminuyendo la respuesta inflamatoria en las infecciones crónicas (Calvo D., 2012; Hernández López J. C., 2012).

Otros estudios han sustentado que los niveles de citocinas sirven también para observar y vigilar la evolución clínica de pacientes con patologías pulmonares y cardíacas (en urgencias y unidades de cuidados críticos), como predictor del pronóstico, así como para valorar la respuesta a los tratamientos. Se puede medir los niveles de interleucinas proinflamatorias en la orina de pacientes mayores para diagnosticar infecciones urinarias cuando estas presentan la sintomatología pertinente, al adicionar los niveles de proteína reactiva $C$ (PCR); también se pueden utilizar como marcadores posquirúrgicos de posibles infecciones. Se encuentra además que los valores elevados de citocinas mejoran la respuesta inmune ante cualquier noxa, especialmente en ancianos con comorbilidades asociadas (Beloosesky, 2007; Bruunsgaard $\mathrm{H}, 2000$; Gentile et al., 2014; Giovannini et al., 2011; Hasegawa, Sawada, Ozaki, Inagaki, y Suzumura, 2000; A. T. Kumar et al., 2009; Lechner et al., 2013; Leng, Chaves, Koenig, y Walston, 2002; Rodhe, Lofgren, Strindhall, Matussek, y Molstad, 2009). 
En la vejez disminuyen, tanto la respuesta a infecciones pulmonares como la expresión génica antiviral, los niveles de citocinas proinflamatorias y de osteopontina (Wong et al., 2014). También se afectan los niveles de citocinas (PDGF, bFGF y el IGF-1) esenciales para la remodelación de tejidos lesionados en fibrosis pulmonar y displasia broncopulmonar (Burón Martínez E, Blanco Quirós A., Garrote, J. A. et al., 1998); mientras que en la enfermedad pulmonar obstructiva crónica (EPOC) aumentan los niveles de TNF-a y PCR de acuerdo con la gravedad de esta (Amer M. S., 2010). Cabe anotar que al bajar los niveles de citocinas (IL-1, IL-2, IL-6, IL-8) es posible reducir la inflamación de las vías respiratorias en pacientes con hiperreactividad bronquial y en asmáticos (Krakauer y Russo, 2001; Krug et al., 2015).

Recientemente se ha demostrado que los pacientes pueden presentar mayor o menor cantidad de citocinas (IL-2) y de células NK en función de los grupos de alelos según su disposición genética, así como que los pacientes diagnosticados de linfoma presentan una mejoría en su condición clínica significativa al ser tratados con células estimuladas por citocinas autólogas (Lu et al., 2012; Rea et al., 2013).

En el ejercicio físico se presentan respuestas inmunes notablemente similares en muchos aspectos a las que son inducidas por las infecciones, la sepsis o los traumatismos. Con el ejercicio se incrementa el número de leucocitos (linfocitos y neutrófilos) y este incremento se relaciona con la intensidad y duración del mismo, además de que hay un aumento de citocinas inflamatorias TNF-a, macrófagos, IL-1; citocinas antiinflamatorias (IL-4, IL-6, IL13, IL-15, TNFa, MIP-1b); y proteínas de fase aguda (PCR) que aportan energía y resistencia cardiovascular. Con la modulación de algunas citocinas mieloperoxidasa (MPO), las proteí- nas de choque térmico (HSP70 y HSP27) y la tiorredoxina reductasa 1 ( $\operatorname{TrXR} 1$ ) se reduce la inflamación producida por el ejercicio intenso, además que se da una disminución de la fatiga muscular (Beenakker et al., 2014; Beltran Valls et al., 2014; Kawaguchi, Shiba, Takano, Maeda, y Sata, 2011; Kumar et al., 2014; Lambert C. P., 2008; Nicklas et al., 2008; Pereira et al., 2013; Rajbhoj, Shete, Verma, y Bhogal, 2015; Silva et al., 2011).

Igualmente, datos aportados por investigaciones posteriores al 2005 han demostrado que los incrementos en la síntesis y en la secreción de citocinas (IL-1 y IL-6) en sujetos ancianos tienen efectos negativos a nivel osteoarticular, debido a la pérdida de osteoblastos, además de que contribuye al deterioro en patologías inflamatorias relacionadas con la edad, como la osteoporosis y la osteoartritis. Los pacientes con polimialgia reumática, artritis reumatoide y dolor lumbar crónico causado por hernias discales, presentan mayores niveles de citocinas (TNF- a y IL-6, pero no de IL-1, ni sTNF-R), situación que mejora con un manejo farmacológico basado en glucocorticoides (Campos Kraychete D., 2010; Cutolo et al., 2006; Eriksen et al., 2010; Gomes et al., 2012; Marti et al., 2007).

El sistema inmune en sujetos sanos de edad avanzada puede favorecerse a partir de una suplementación dietética con probióticos de lactobacillus; se pudo observar que el fortalecimiento del sistema inmune aumentó el porcentaje de células NK, el retardo del envejecimiento de linfocitos $T$; hubo una disminución de los niveles de IL-8 y un aumento de IL-2, gracias a este suplemento. Sin embargo, al suspender la ingesta de probióticos disminuyeron también sus efectos, demostrando una clara asociación entre estos (Hibberd et al., 2014; Kikuchi, Inagaki, Shinagawa, y Ueda, 2004; Moro-García et al., 2013). 
En el envejecimiento, el estrés oxidativo produce cambios notorios en el sistema nervioso central, presentando predisposición a patologías neurológicas degenerativas como el alzheimer (Honma et al., 2013; Jozwik et al., 2012; Kilpatrick et al., 2008). La fisiopatología de este tipo de demencias involucra linfocitos T CD4+ y CD28+ estimulados por interleucinas (IL-1ß, IL-6 e IL-10), marcadores que permiten el estudio y diagnóstico de estas enfermedades (Nagai, Kozaki, Sonohara, Akishita, y Toba, 2011). El delirium es un proceso patológico bastante común en pacientes ancianos, el cual está asociado al aumento de citocinas proinflamatorias halladas en infecciones sistémicas (Adamis et al., 2007), y a estados posoperatorios prolongados (Jia et al., 2014); mientras que en cirugías de corta duración donde hay menores niveles de estas citocinas, el delirium es menos frecuente (Westhoff et al., 2013). También se ha manifestado que las células neuronales y la producción de citocinas interfieren en la fisiopatología de trastornos neuropsiquiátricos. En este contexto se plantean variaciones genéticas asociadas con demencias y niveles elevados de marcadores inflamatorios que se han correlacionado con alteraciones conductuales, bajo rendimiento cognitivo y pobre calidad de vida (Arisi, 2014; Baierle et al., 2015; Sudheimer et al., 2014; Tu et al., 2014; Verschoor et al., 2014).

La presencia de polimorfismos genéticos en la IL-6 puede darse por variaciones genéticas que podrían estar influenciadas por la edad (Pereira et al., 2013). Las mujeres presentan mayores niveles de esta citocina, lo cual mejora su supervivencia (Cederholm et al., 2007). Otras citocinas se ven aumentadas en el hombre con los mismos efectos. Algunas variaciones genotípicas de la IL-6 no son tan benevolentes con el adulto mayor, ya que se relacionan con mayor incidencia con cáncer de pulmón, fibrilación auricular (Li et al., 2012) y enfermedad arterial oclusiva periférica (Garofolo, Ferreira, y Miranda Junior, 2014). Por su parte, el TNF-a se liga con mayor deficiencia auditiva en adultos mayores, participando en la patogénesis de la respuesta inflamatoria inadecuada y en el desequilibrio entre la proliferación celular y apoptosis (Uchida Y. et al., 2014).

Se concluye que las citocinas se presentan como una estrategia para diagnosticar, tratar y controlar la evolución de enfermedades relacionadas con las alteraciones de la inflamación y de procesos inmunes, abriendo nuevas alternativas para desarrollar métodos diagnósticos y tratamientos innovadores que favorezcan la salud de las personas.

\section{Agradecimientos}

Agradecemos la revisión del texto y la asesoría metodológica al docente Jairo León Cardona Jiménez, docente investigador de la Facultad de Ciencias de la Salud de la Corporación Universitaria Remington.

\section{Glosario}

Antagonismo: inhibición o bloqueo mutuo de efectos.

APOE: apoproteína y principal componente en los quilomicrones.

ARNm: ácido ribonucleico mensajero. 
bFGF: (Basic Fibroblast Growth Factor) factor de crecimiento de fibroblasto básico.

Células dendríticas: procesa material antigénico para llevarlos a la superficie y presentarlo a las células especializadas del sistema inmunitario.

Citocinas Th2: interleucina 4, interleucina 5, interleucina 6, interleucina 9, interleucina 10 e interleucina 13.

CRP. proteína C reactiva.

CSF: factores estimuladores de colonia.

GLUT4: (Glucose transporter type 4) proteína transportadora de glucosa regulada por la insulina que se localiza en los adipocitos, en el músculo esquelético y en el miocardio.

Haplotipos: polimorfismo de un solo nucleótido en un cromosoma particular, estadísticamente asociados.

Hsp70: proteínas de shock térmico de $70 \mathrm{KDa}$ o Hsp70 necesarias para el desarrollo de la fisiología celular.

IGF-1: el factor de crecimiento insulínico tipo 1 o somatomedina $\mathrm{C}$.

IL: interleucina.

IFN: interferón.

KIR: (Killer-cell immunoglobulin-like receptors) receptores de las células NK.

LPS: lipopolisacárido.

MGF: factor de crecimiento mecánico.

MIP-1b: Macrophage Inflammatory Protein-1 $\beta$.
Monocitos: células sanguíneas de línea blanca, agranulocitos; su función es fagocitar.

MCP. proteína cofactor de membrana.

NF-kappa B: factor nuclear potenciador de las cadenas ligeras kappa de las células B activadas.

NK: (Natural Killer) células asesinas naturales.

OPN: osteopontina; proteína multifuncional que participa en la mineralización ósea; en la adherencia celular; en la migración celular; enfermedad inflamatoria crónica y en transformación.

PCR: proteína $C$ reactiva.

PDGF: (Platelet derived growth factor) factor de crecimiento derivado de plaquetas.

Quimiocina: proteínas de tamaño pequeño que pertenecen a la familia de las citocinas quimiotácticas.

Quinasas de Janus: (JAK) proteínas pertenecientes a las enzimas asociadas a receptores de citocinas; son tirosinas quinasas no específicas.

PI3K phosphoinositide 3-quinasa: familia de enzimas capaces de fosforilar el grupo hidróxilo de las moléculas fosfatidilinositol en humanos, codificada por el gen PIK3CD.

Pleiotropía: múltiples efectos de las citocinas al actuar sobre diferentes células.

Redundancia: varias citocinas que pueden ejercer el mismo efecto.

Sinergismo: cuando dos o más citocinas producen un efecto que se potencia mutuamente.

sTNF-R: formas solubles del receptor de factor de necrosis tumoral. 
TGF- $\boldsymbol{\beta}$ : factor de crecimiento transformante beta.

TNF: factor de necrosis tumoral.

TLR: (Toll-like receptor) receptor tipo Toll.

TNFRSF1B: (Tumor Necrosis Factor Receptor Superfamily) receptor de la superfamília de factor de necrosis tumoral.

\section{Referencias bibliográficas}

Adamis, D., Treloar, A., Martin, F. C., Gregson, N., Hamilton, G., y Macdonald, A. J. (2007). APOE and cytokines as biological markers for recovery of prevalent delirium in elderly medical inpatients. Int J Geriatr Psychiatry, 22(7), 688-694. doi: 10.1002/gps.1732

Aguirre de Avalos M. V, Quintana R, Brandan N. (2002). Citoquinas. . Universidad Nacional del Nordeste - Facultad de Medicina Cátedra de Bioquímica., 19(1), 1-2.

- Arisi, G. M. (2014). Nervous and immune systems signals and connections: cytokines in hippocampus physiology and pathology. Epilepsy Behav, 38, 43-47. doi: 10.1016/j. yebeh.2014.01.017

- Baierle, M., Nascimento, S. N., Moro, A. M., Brucker, N., Freitas, F., Gauer, B., García, S. C. et al. (2015). Relationship between inflammation and oxidative stress and cognitive decline in the institutionalized elderly. Oxid Med Cell Longev, 2015, 804198. doi: $10.1155 / 2015 / 804198$

- Beenakker, K. G, Koopman, J. J, Bodegom, D, Kuningas, M, Slagboom, P. E, Meij, J. J, y
Westendorp, R. G. (2014). Variants of the IL 10 gene associate with muscle strength in elderly from rural Africa: a candidate gene study. Aging cell, 13(5), 862-868.

Beltrán Valls, M. R., Dimauro, I., Brunelli, A., Tranchita, E., Ciminelli, E., Caserotti, P., Caporossi, D. et al. (2014). Explosive type of moderate-resistance training induces functional, cardiovascular, and molecular adaptations in the elderly. Age (Dordr), 36(2), 759-772. doi: 10.1007/s11357-013-9584-1

- Campos Kraychete D, Kimiko Sakata R., Machado Issy A., Bacellar O., Santos-Jesus R., Carvalho E. M. (2010). Serum cytokine levels in patients with chronic low back pain due to herniated disc: analytical cross-sectional study. Sao Paulo Med J., 128(5), 259262.

- Cardella H. L., Hernández R, Upnonn C., Vicedo A., Pérez A., Sierra S, et al. (1999). Componentes celulares y genética molecular. Bioquímica médica. La Habana: Editorial Ciencias Médicas, tomo 2, 25.

Cederholm, T., Persson, M., Andersson, P., Stenvinkel, P., Nordfors, L., Madden, J., Palmblad, J. et al. (2007). Polymorphisms in cytokine genes influence long-term survival differently in elderly male and female patients. J Intern Med, 262(2), 215-223. doi: 10.1111/j.1365-2796.2007.01803.x

Cotran R. S., Kumar, V., Collins, T. (1999). Patología estructural y funcional. Madrid: Mc Graw Hill, Interamericana, 6 ed, 1-95.

- Cutolo, M., Montecucco, C. M., Cavagna, L., Caporali, R., Capellino, S., Montagna, P., Sulli, A. et al. (2006). Serum cytokines and steroidal hormones in polymyalgia rheuma- 
tica and elderly-onset rheumatoid arthritis. Ann Rheum Dis, 65(11), 1438-1443. doi: 10.1136/ard.2006.051979

Eriksen, C. G., Olsen, H., Husted, L. B., Sorensen, L., Carstens, M., Soballe, K., y Langdahl, B. L. (2010). The expression of IL- 6 by osteoblasts is increased in healthy elderly individuals: stimulated proliferation and differentiation are unaffected by age. Calcif Tissue Int, 87(5), 414-423. doi: $10.1007 / \mathrm{s} 00223-010-9412-x$

- Filella X., Molina R., Ballesta A. M. (2002). Estructura y función de las citocinas. Med. Integral 39(2), 67-71.

- Garofolo, L., Gouvea Ferreira, S. y Miranda Junior, F. (2014). Biomarkers of inflammation may be of use for identification of more severe peripheral arterial occlusive disease. J Vasc Bras, 13(3), 182-191. doi: $10.1590 /$ jvb.2014.045

Gomes, W. F., Lacerda, A. C., Mendonca, V. A., Arrieiro, A. N., Fonseca, S. F., Amorim, M. R., Brito-Melo, G. E. et al. (2012). Effect of aerobic training on plasma cytokines and soluble receptors in elderly women with knee osteoarthritis, in response to acute exercise. Clin Rheumatol, 37(5), 759-766. doi: 10.1007/s10067-011-1927-7

- Guirao y Alonso. (2006). Guía clínica de infecciones quirúrgicas. Arán Ediciones(597), 47-57.

Hibberd, P. L., Kleimola, L., Fiorino, A. M., Botelho, C., Haverkamp, M., Andreyeva, I., Snydman, D. R. et al. (2014). No evidence of harms of probiotic Lactobacillus rhamnosus GG ATCC 53103 in healthy elderly-a phase I open label study to assess safety, tolerability and cytokine responses. PLOS One, 9(12), e113456. doi: 10.1371/journal. pone. 0113456

Honma, T., Hatta, K., Hitomi, Y., Kambayashi, Y., Hibino, Y., Konoshita, T., y Nakamura, H. (2013). Increased systemic inflammatory interleukin-1ss and interleukin-6 during agitation as predictors of Alzheimer's disease. Int J Geriatr Psychiatry, 28(3), 233241. doi: 10.1002/gps.3816

Jia, Y., Jin, G., Guo, S., Gu, B., Jin, Z., Gao, X., y Li, Z. (2014). Fast-track surgery decreases the incidence of postoperative delirium and other complications in elderly patients with colorectal carcinoma. Langenbecks Arch Surg, 399(1), 77-84. doi: 10.1007/s00423013-1151-9

Jozwik, A., Landowski, J., Bidzan, L., Fulop, T., Bryl, E., y Witkowski, J. M. (2012). Beta-amyloid peptides enhance the proliferative response of activated CD4CD28 lymphocytes from Alzheimer disease patients and from healthy elderly. PLoS One, 7(3), e33276. doi: 10.1371/journal. pone. 0033276

Kawaguchi, T., Shiba, N., Takano, Y., Maeda, T., y Sata, M. (2011). Hybrid training of voluntary and electrical muscle contractions decreased fasting blood glucose and serum interleukin- 6 levels in elderly people: a pilot study. Appl Physiol Nutr Metab, 36(2), 276283. doi: 10.1139/h10-108

Kikuchi, M., Inagaki, T., Shinagawa, N., y Ueda, R. (2004). Clinical significance of the soluble interleukin-2 receptor as a putative systemic nutritional index in the elderly. Geriatrics \& Gerontology International, 4(1), 31-36. 
- Kilpatrick, R. D., Rickabaugh, T., Hultin, L. E., Hultin, P., Hausner, M. A., Detels, R., y Jamieson, B. D. (2008). Homeostasis of the naive CD4+ $T$ cell compartment during aging. The Journal of Immunology, 180(3), 1499-1507.

- Kumar, J., Lind, P. M., Salihovic, S., van Bavel, B., Ingelsson, E., y Lind, L. (2014). Persistent organic pollutants and inflammatory markers in a cross-sectional study of elderly swedish people: the PIVUS cohort. Environ Health Perspect, 122(9), 977-983. doi: 10.1289/ehp. 1307613

- Lambert C. P, Wright N. R., Finck B. N., Villareal D. T. (2008). Exercise but not diet-induced weight loss decreases skeletal muscle inflammatory gene expression in frail obese elderly persons. $J$ Appl Physiol 105(2), 473-478.

Li, J., Song, J., Jiang, M. H., Zheng, J. G., Gao, S. P., Zhu, J. H., y Pan, M. (2012). Interleukin-6 promoter polymorphisms and susceptibility to atrial fibrillation in elderly Han Chinese patients with essential hypertension. J Interferon Cytokine Res, 32(11), 542-547. doi: 10.1089/jir.2012.0033

- Marti, L., Cervera, C., Filella, X., Marin, J. L., Almela, M., y Moreno, A. (2007). Cytokinerelease patterns in elderly patients with systemic inflammatory response syndrome. Gerontology, 53(5), 239-244. doi: 10.1159/000101436

Moro-García, M. A., Alonso-Arias, R., Baltadjieva, M., Fernández Benítez, C., Fernandez Barrial, M. A., Díaz Ruisanchez, E., López-Larrea, C. et al. (2013). Oral supplementation with Lactobacillus delbrueckii subsp. bulgaricus 8481 enhances systemic immunity in elderly subjects. Age (Dordr), 35(4), 1311-1326. doi: 10.1007/ s11357-012-9434-6

Nagai, K., Kozaki, K., Sonohara, K., Akishita, M., y Toba, K. (2011). Relationship between interleukin- 6 and cerebral deep white matter and periventricular hyperintensity in elderly women. Geriatr Gerontol Int, 11(3), 328-332. doi: 10.1111/j.1447-0594.2010.00686.x

Nicklas, B. J., Hsu, F. C., Brinkley, T. J., Church, T., Goodpaster, B. H., Kritchevsky, S. B., y Pahor, M. (2008). Exercise training and plasma C-reactive protein and interleukin-6 in elderly people. J Am Geriatr Soc, 56(11), 2045-2052. doi: 10.1111/j.15325415.2008.01994.x

Pereira, D. S., Mateo, E. C., de Queiroz, B. Z., Assumpcao, A. M., Miranda, A. S., Felicio, D. C., Pereira, L. S. (2013). TNF-alpha, IL6, and IL10 polymorphisms and the effect of physical exercise on inflammatory parameters and physical performance in elderly women. Age (Dordr), 35(6), 2455-2463. doi: 10.1007/ s11357-013-9515-1

- Rajbhoj, P. H., Shete, S. U., Verma, A., y Bhogal, R. S. (2015). Effect of yoga module on pro-inflammatory and anti-inflammatory cytokines in industrial workers of lonavla: a randomized controlled trial. J Clin Diagn Res, 9(2), CC01-05. doi: 10.7860/ JCDR/2015/11426.5551

- Silva, J. P., Pereira, D. S., Coelho, F. M., Lustosa, L. P., Dias, J., y Pereira, L. S. (2011). Clinical, functional and inflammatory factors associated with muscle fatigue and self-perceived fatigue in elderly community-dwelling women. Brazilian Journal of Physical Therapy, 15(3), 241-248. 
- Sudheimer, K. D., O'Hara, R., Spiegel, D., Powers, B., Kraemer, H. C., Neri, E., Dhabhar, F. S. (2014). Cortisol, cytokines, and hippocampal volume interactions in the elderly. Front Aging Neurosci, 6, 153. doi: 10.3389/ fnagi.2014.00153

- Tu, P. C., Su, T. P., Huang, C. C., Yang, A. C., Yeh, H. L., Hong, C. J., Tsai, S. J. (2014). Interleukin-1 beta C-511T polymorphism modulates functional connectivity of anterior midcingulate cortex in non-demented elderly Han males. Brain Struct Funct, 219(1), 61-69. doi: 10.1007/s00429-012-0484-4

Uchida Y., Sugiura S., Ueda H., Nakashima T., Ando .F, y Shimokata, H. (2014). The association between hearing impairment and polymorphisms of genes encoding inflam- matory mediators in Japanese aged population. 2014, 11(1), 18.

- Verschoor, C. P., Johnstone, J., Millar, J., Parsons, R., Lelic, A., Loeb, M., y Bowdish, D. M. (2014). Alterations to the Frequency and Function of Peripheral blood Monocytes and Associations with Chronic Disease in the Advanced-Age, Frail Elderly. PLoS One, 9(8), e104522. doi: 10.1371/journal. pone.0104522.t001

Westhoff, D., Witlox, J., Koenderman, L., Kalisvaart, K. J., De Jonghe, J. F., Van Stijn, M. F., y van Gool, W. A. (2013). Preoperative cerebrospinal fluid cytokine levels and the risk of postoperative delirium in elderly hip fracture patients. J Neuroinflammation, 10(122), 2094-2010. 